\title{
Transient stability of 11-bus system using SVC and improvement of voltage profile in transmission line using series compensator
}

\author{
Ramlal Das, D. K. Tanti \\ Electrical Engineering Department, Bit Sindri \\ Email address: \\ ramla10326@gmail.com (R. Das),dktanti66@gmail.com (D. K. Tanti)
}

To cite this article:

Ramlal Das, D. K. Tanti. Transient Stability of 11-Bus System Using SVC and Improvement of Voltage Profile in Transmission Line Using Series Compensator. American Journal of Electrical Power and Energy Systems. Vol. 3, No. 4, 2014, pp. 76-85. doi: $10.11648 /$ j.epes.20140304.12

\begin{abstract}
Power system stability is defined as the ability of power system to preserve its steady stability or recover the initial steady state after any deviation of the system's operation. Present time power systems are being operated nearer to their stability limits due to economic and environmental reasons. Maintaining a stable and secure operation of a power system is therefore a very important and challenging issue. Transient stability has been given much attention by power system researchers and planners in recent years, and is being regarded as one of the major sources of power system insecurity. Shunt FACTS devices play an important role in improving the transient stability, increasing transmission capacity and damping low frequency oscillations. In this work 11-bus power system network has been modeled using MATLAB SIMULINK software. The power system network under study consist of three units of power plant each producing $20 \mathrm{KV}$ and step up by two winding transformer to $230 \mathrm{KV}$. For parallel operation of two different power plants, the frequency and the terminal voltage has been kept constant to avoid circulating current in the existing network. A Static VAR Compensator and a series compensator have been used in the considered network for improving the transient stability and to increase the transmission capacity of the system.
\end{abstract}

Keywords: Power System Stability, Transient Stability, SVC, Series Compensator

\section{Introduction}

Power systems generally consist of three stages: generation, transmission, and distribution. In the first stage, generation, the electric power is generated mostly by using synchronous generators. Then the voltage level is raised by transformers before the power is transmitted in order to reduce the line currents which consequently reduce the power transmission losses. After the transmission, the voltage is stepped down using transformers in order to be distributed accordingly. Power systems are designed to provide continuous power supply that maintains voltage stability. However, due to undesired events, such as lightning, accidents or any other unpredictable events, short circuits between the phase wires of the transmission lines or between a phase wire and the ground which may occur is called a fault. Due to occurring of a fault, one or more generators may be severely disturbed causing an imbalance between generation and demand. If the fault persists and is not cleared in a pre-specified time frame, it may cause severe damages to the equipment's which in turn may lead to a power loss and power outage. Therefore, protective equipment's are installed to detect faults and clear/isolate faulted parts of the power system as quickly as possible before the fault energy is propagated to the rest of the system.

\section{Literature Review}

For the purpose of this review, a literature survey has been carried out including two of the most important and common databases, namely, the IEEE/IEE electronic library and Science Direct electronic databases. The survey spans over the last 15 years from 1990 to 2004. For 
convenience, this period has been divided to three subperiods; 1990-1994, 1995-1999, and 2000-2004. The number of publications discussing FACTS applications to different power system studies has been recorded. The results of the survey are shown in Figure 1. It is clear that the applications of FACTS to different power system studies have been drastically increased in last five years. This observation is more pronounced with the second generation devices as the interest is almost tripled. This shows more interest for the VSC-based FACTS applications. The results also show a decreasing interest in TCPS while the interest in SVC and TCSC slightly increase. Generally, both generations of FACTS have been applied to different areas in power system studies including optimal power flow [5-9], economic power dispatch [20], voltage stability [11;22], power system security [3], and power quality [7].

Applications of FACTS to power system stability in particular have been carried out using same databases. The results of this survey are shown in Figure 7. It was found that the ratio of FACTS applications to the stability study with respect to other power system studies is more than $60 \%$ in general.

\section{Classification of Stability}

Figure 1.1 provides a comprehensive categorization of power system stability. As Depicted by Figure 1, there are two main classes of stability: rotor angle stability and voltage stability. Rotor angle stability has two main subclasses: small-disturbance angle (steady-state) stability and transient stability. A power system is considered to be steady-state stable if, after any small disturbance, it reaches a steady state operating condition which is identical or close to the pre disturbance operating condition. A power system is transient stable for a large disturbance or sequence of disturbances if, following that disturbances it reaches an acceptable steady-state operating condition. Unlike steady-state stability which is a function only of the operating condition, transient stability is more complicated since it is a function of both operating condition and the disturbance [2]. Voltage stability also has two main subclasses: large disturbance voltage stability and small disturbance voltage stability.

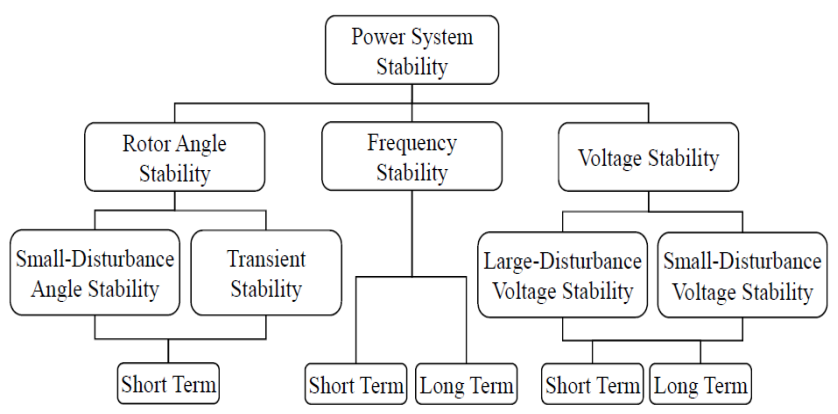

Figure 1. Classification of power system stability

\section{Transient Stability}

Transient stability is the ability of the power system to maintain synchronism when subjected to sever transient disturbance. The response to this type of disturbance involves large excursions of rotor angles and is influenced by nonlinear power-angle relationship. Stability depends on the initial operating state of the system and the severity of the disturbance. The system usually altered after the disturbance which may cause the system to operate in a different steady-state status from that prior the disturbance. Power systems are designed to be stable for a selected set of contingencies. The contingencies usually considered are short-circuits of different types: phase-to-ground, phase-to phase- to-ground, or three-phase. They are usually assumed to occur on the transmission lines, but occasionally bus or transformer faults are also considered. Figure 2.1 illustrates the behavior of a synchronous machine for stable and unstable situations. In Case 1, the rotor angle increases to a maximum, then decreases and oscillates with decreasing amplitude until it reaches a steady state. This case is considered transient stable. In Case 2, the rotor angle continues to increase steadily until synchronism is lost. This type on transient instability is referred to as first-swing instability. In Case 3, the system is stable in the first swing but becomes unstable as a result of growing oscillations as the end state is approached. This form of instability occurs when the post fault steady-state condition is itself is smallsignal unstable. In transient stability studies, the study period of interest is usually limited to 3 to 5 seconds following the disturbance, although it may extend to about ten seconds for very large systems with dominant inter area modes of oscillation.

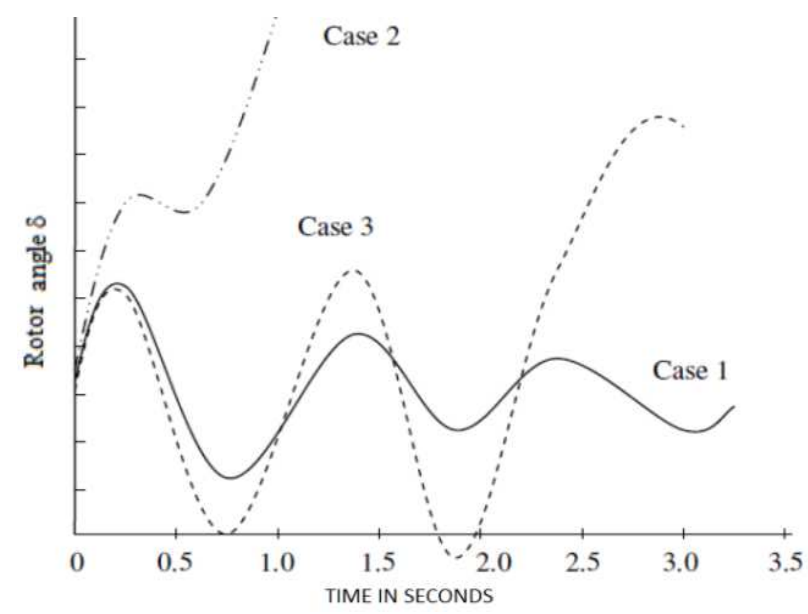

Figure 2. Rotor angle response to a transient disturbance.

Methods of transient stability analysis

1. Swing equation

2. Equal area criterion

3. Numerical Integration Methods

4. Direct Methods Transient Stability Analysis 


\section{Static Var Compensator (SVC)}

The Static Var Compensator (SVC) is a shunt device of the Flexible AC Transmission Systems (FACTS) family using power electronics to control power flow and improve transient stability on power grids [1]. The SVC regulates voltage at its terminals by controlling the amount of reactive power injected into or absorbed from the power system. When system voltage is low, the SVC generates reactive power (SVC capacitive). When system voltage is high, it absorbs reactive power (SVC inductive). The variation of reactive power is performed by switching three-phase capacitor banks and inductor banks connected on the secondary side of a coupling transformer. Each capacitor bank is switched on and off by three thyristor switches (Thyristor Switched Capacitor or TSC). Reactors are either switched on-off (Thyristor Switched Reactor or TSR) or phase-controlled (Thyristor Controlled Reactor or TCR).

It is a variable impedance device where the current through a reactor is controlled using back to back connected thyristor valves. The application of thyristor valve technology to SVC is an offshoot of the developments in HVDC technology. The major difference is that thyristor valves used in SVC are rated for lower voltages as the SVC is connected to an EHV line through a step down transformer or connected to the tertiary winding of a power transformer.

The application of SVC was initially for load compensation of fast changing loads such as steel mills and arc furnaces. Here the objective is to provide dynamic power factor improvement and also balance the currents on the source side whenever required. The application for transmission line compensators commenced in the late seventies. Here the objectives are:

1. Increase power transfer in long lines

2. Improve stability with fast acting voltage regulation

3. Damp low frequency oscillations due to swing (rotor) modes

4. Damp sub synchronous frequency oscillations due to torsional modes

5. Control dynamic over voltages

\subsection{Configuration of SVC}

There are two types of SVC:

1. Fixed Capacitor-Thyristor Controlled Reactor (FCTCR)

2. Thyristor Switched Capacitor (TSC-TCR).

The second type is more flexible than the first one and requires smaller rating of the reactor and consequently generates fewer harmonic. The schematic diagram of a TSC-TCR type SVC is shown in Fig.3 this shows that the TCR and TSC are connected on the secondary side of a step-down transformer. Tuned and high pass filters are also connected in parallel which provide capacitive reactive power at fundamental frequency. The voltage signal is taken from the high voltage SVC bus using a potential transformer.

The TSC is switched in using two thyristor switches (connected back to back) at the instant in a cycle when the voltage across valve is minimum and positive. This results in minimum switching transients. In steady state, TSC does not generate any harmonics. To switch off a TSC, the gate pulses are blocked and the thyristors turns off when the current through them fall below the holding currents. It is to be noted that several pairs of thyristors are connected in series as the voltage rating of a thyristor is not adequate for the voltage level required. However the voltage ratings of valves for a SVC are much less than the voltage ratings of a HVDC valve as a step down transformer is used in the case of SVC. To limit $\frac{d i}{d t}$ in a TSC it is necessary to provide a small reactor in series with the capacitor.

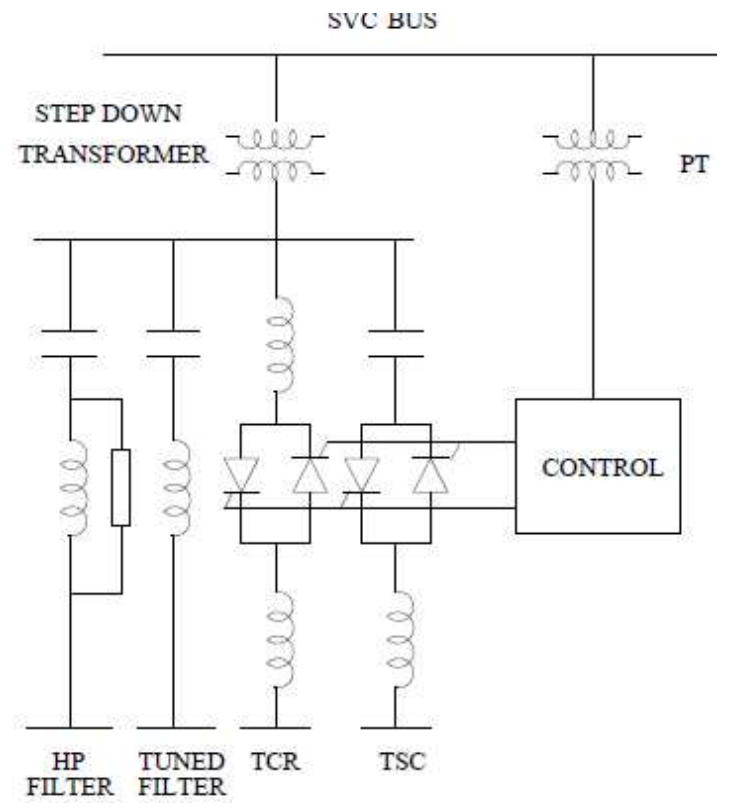

Figure 3. A Typical SVC (TSC-TCR) Configuration

\subsection{SVC Controller}

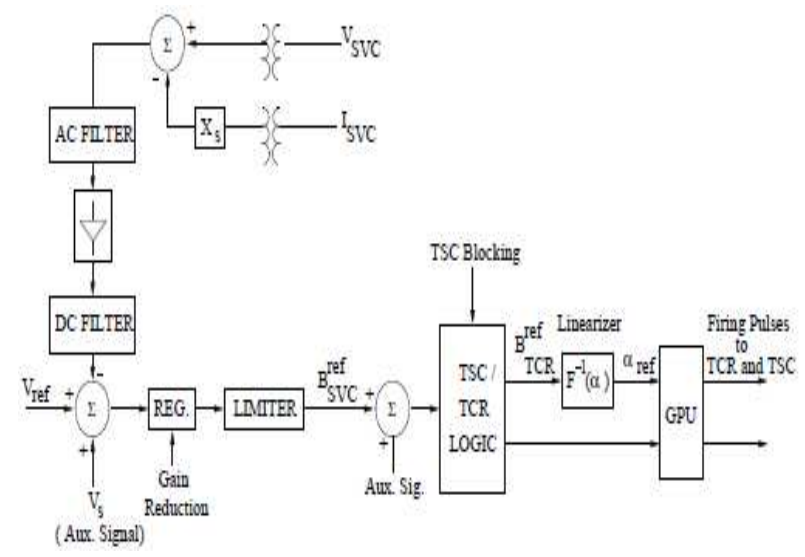

Figure 4. SVC Controller

The block diagram of basic SVC Controller incorporating voltage regulator is shown in Fig.4 This shows that both voltage $\left(V_{S V C}\right)$ and current $\left(I_{S V C}\right)$ signals 
are obtained from potential and current transformers and then rectified. The AC filter is basically a notch filter to eliminate the signal component of frequency corresponding to the parallel resonance in the system viewed from the SVC bus. The line capacitance (in parallel with SVC capacitance) can result in parallel resonance with the line inductance. The SVC voltage regulator has a tendency to destabilize this resonant mode of oscillation and the notch filter is aimed at overcoming this problem. As a matter of fact, any parallel resonance mode (of frequency below second harmonic) can have adverse interaction with SVC voltage regulator. If series capacitors are used along with SVC, then they can cause parallel resonance with a neighboring shunt reactor. If the second (parallel resonance) mode has a lower frequency (say below $20 \mathrm{~Hz}$ ), a high pass filter in addition to the notch filter has been suggested

The rectified signal is filtered. The DC side filters include both a low pass filter (to remove the ripple content) and notch filters tuned to the fundamental and second harmonic components. The notch filters are provided to avoid the adverse interactions of SVC caused by second harmonic positive sequence and fundamental frequency negative sequence voltages on the SVC bus. For example, second harmonic positive sequence voltages at the SVC bus cause a fundamental frequency component in the rectified signal that results in the modulation of SVC susceptance at the same frequency. This in turn (due to amplitude modulation) results in two components at side band frequencies $(0,2 \mathrm{f})$ in the SVC current. The dc component can result in unsymmetric saturation of the SVC transformer and consequent increase in the magnetization current containing even harmonics. It has been observed that this adverse harmonic interaction between the SVC and the network can result in large distortion of the SVC bus voltage and impaired operation of SVC (termed as second harmonic instability).

The auxiliary signals mentioned in Fig.3.2 are outputs from the Susceptance (or reactive power) Regulator (SR) and Supplementary Modulation Controller (SMC). The Susceptance Regulator is aimed at regulating the output of SVC in steady state such that the full dynamic range is available during transient disturbances. The output of Susceptance Regulator modifies the voltage reference $V_{\text {ref }}$ in steady state. However its operation is deliberately made slow such that it does not affect the voltage regulator function during transients.

\section{Series Compensator}

Series capacitors are connected in series with the line conductor to compensate for inductive reactance of the line. This reduces the transfer reactance between the buses to which the line is connected, increases maximum power that can be transmitted, and reduces the effective reactive power $\left(X I^{2}\right)$ loss. Although series capacitors are not usually installed for voltage control as such, they contribute to improved voltage control and reactive power balance. The reactive power produced by a series capacitor increases with increasing power transfer; a series capacitor is selfregulating in this regard.

\subsection{Series Compensation Subsystem}

The three-phase module consists of three identical subsystems, one for each phase. The transmission line is $40 \%$ series compensated by a $62.8 \mu \mathrm{F}$ capacitor. The capacitor is protected by the MOV block. A gap is also connected in parallel with the MOV block. The gap is fired when the energy absorbed by the surge arrester exceeds a critical value of $30 \mathrm{MJ}$. To limit the rate of rise of capacitor current when the gap is fired, a damping RL circuit is connected in series. Open the Energy \& Gap firing subsystem. It shows how you calculate the energy dissipated in the MOV by integrating the power (product of the MOV voltage and current). When the energy exceeds the $30 \mathrm{MJ}$ thresholds, a closing order is sent to the Breaker block simulating the gap.

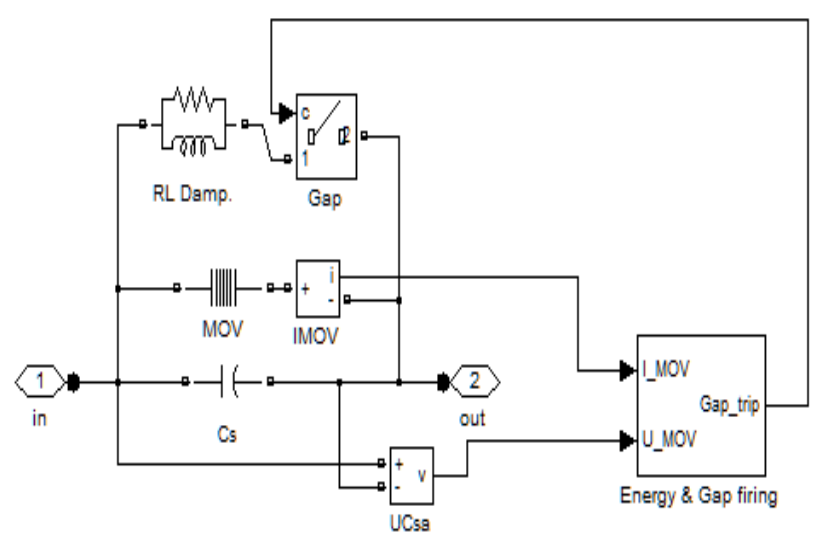

Figure 5. Series Compensation of Subsystem

\section{Simulation and Results}

\subsection{Single Line Diagram of 11-Bus System}

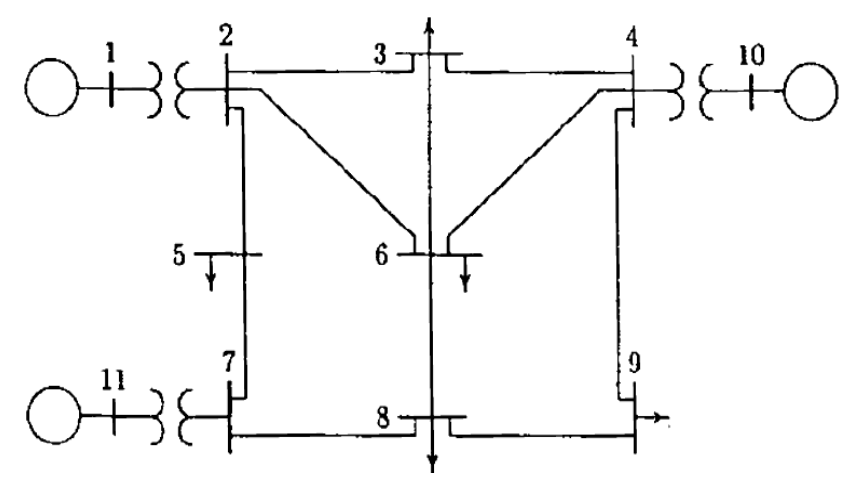

Figure 6. Single Line diagram of 11-bus power system

In this paper three plants has been considered of 900 MW each generating $20 \mathrm{KV}$ and then fed to two winding transformer where voltage is step up to $230 \mathrm{KV}$ and then connected to the transmission system which consist of 11buses. There are five loads connected in the buses 3,5,6,8 and 9 respectively. Simulation model has been developed 
using MATLAB SIMULINK software. A three phase fault has been created near bus no 10 for time 0.01 to $0.03 \mathrm{sec}$ and its impact has been taken down with the help of different bus scopes connected in the model

In the same system I have introduced a series compensator which is $55 \%$ compensated near bus no. 6 to reduce the overshoot caused due to fault and see the amount of overvoltage and over current reduced by the use of it.

\subsection{Simulation Model of 11-Bus System with SVC}

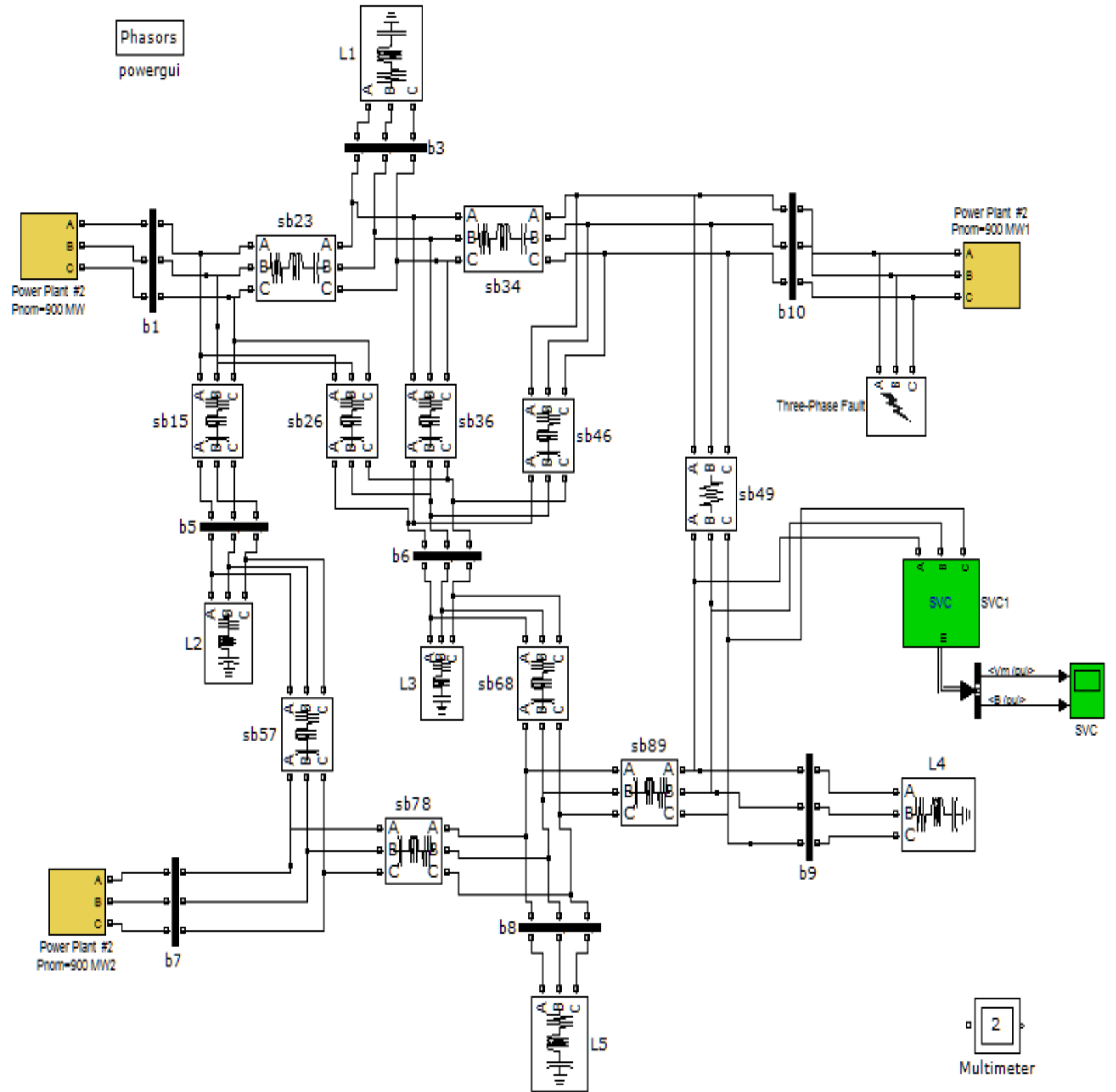

Figure 7. Simulation model of 11-bus system with SVC 


\subsection{Simulation Model of 11-Bus System with Series Compensator}

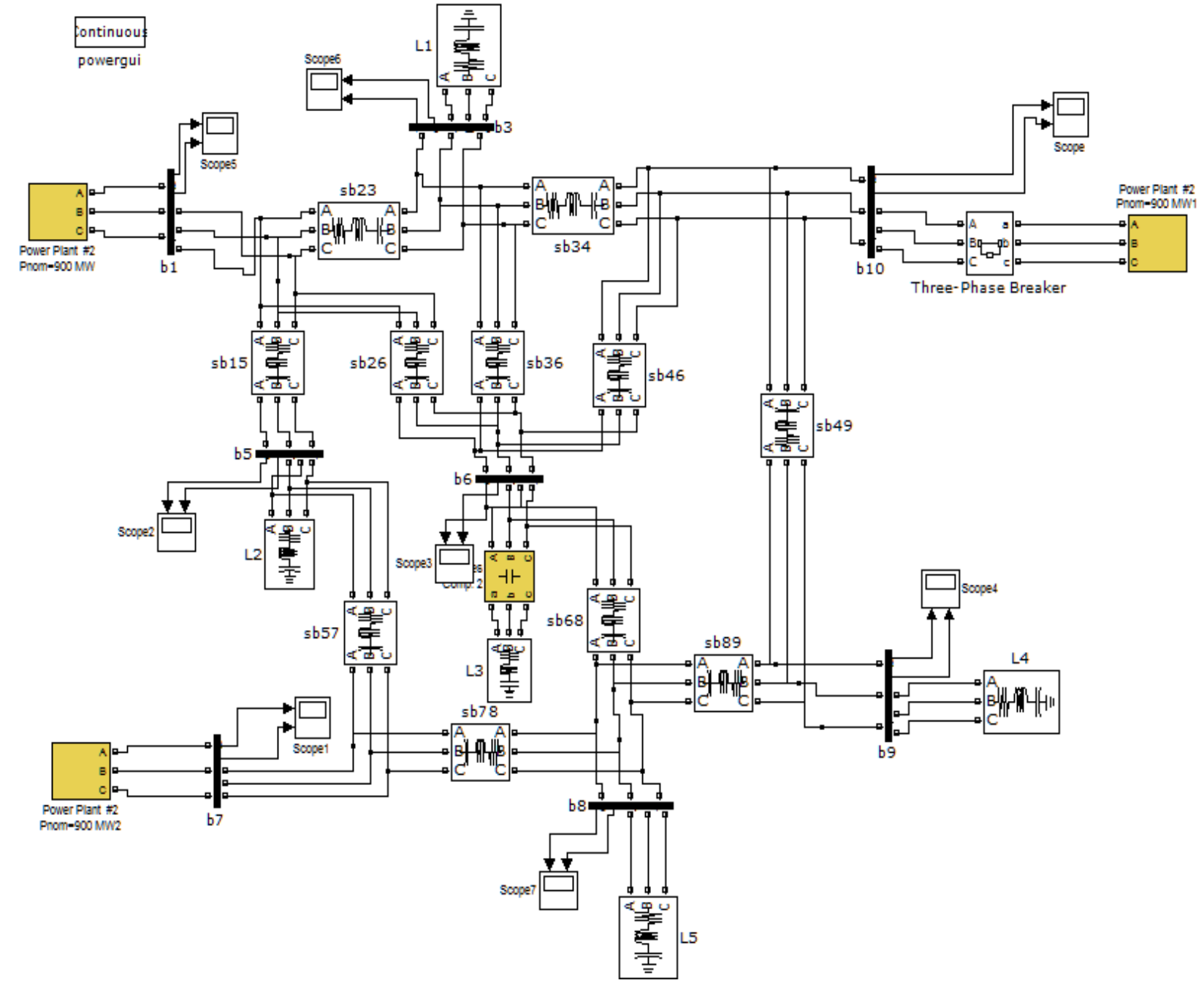

Figure 8. Simulation model of 11 bus system with series compensator

\section{Results}

\subsection{Voltage Waveform of Bus 10 without SVC}

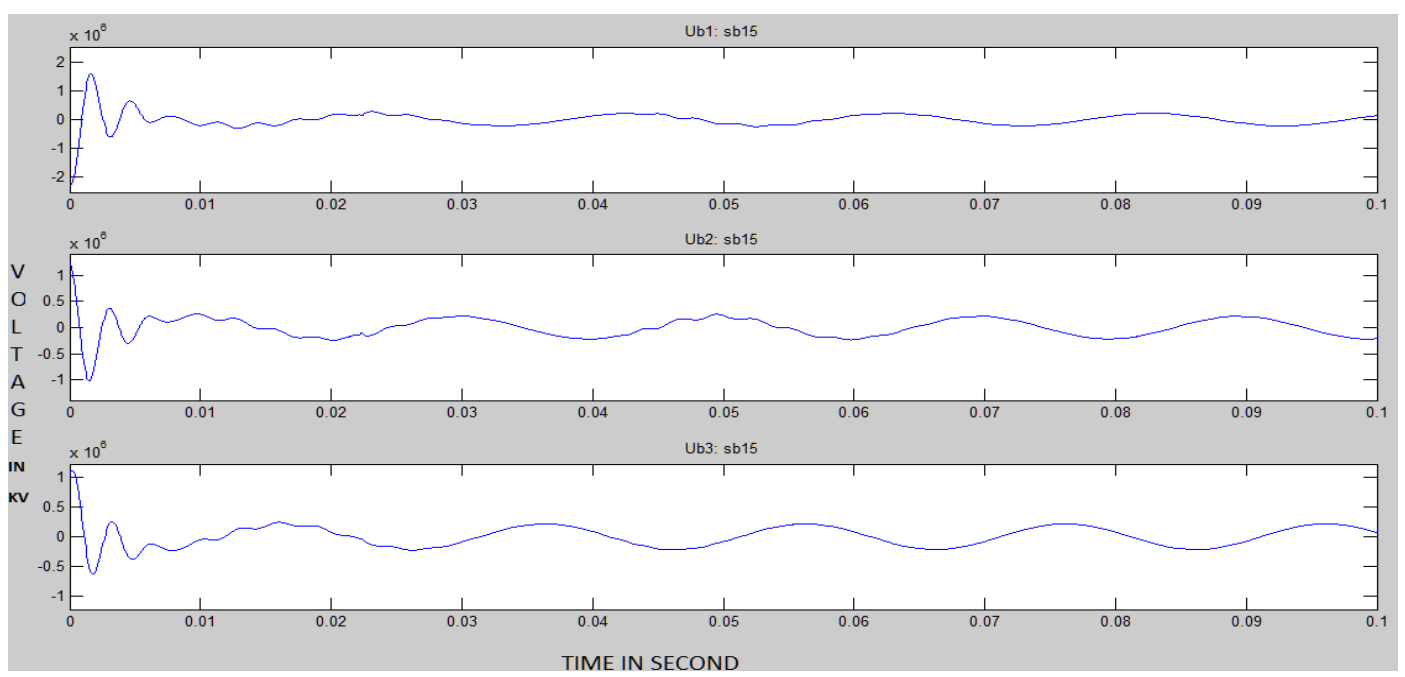

Figure 9. Voltage Waveform of Bus 10 without SVC 


\subsection{Voltage Waveform of Bus 10 with SVC}

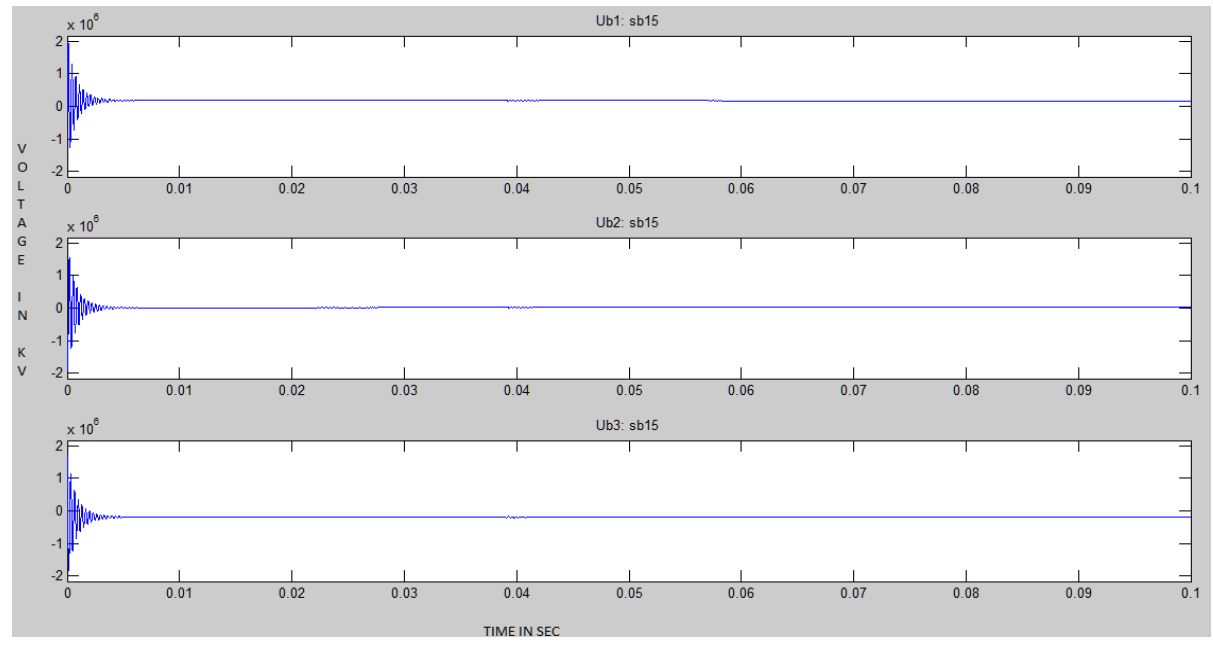

Figure 10. Voltage Waveform of Bus 10 with SVC

\subsection{Current Waveform of Bus 10 without SVC}

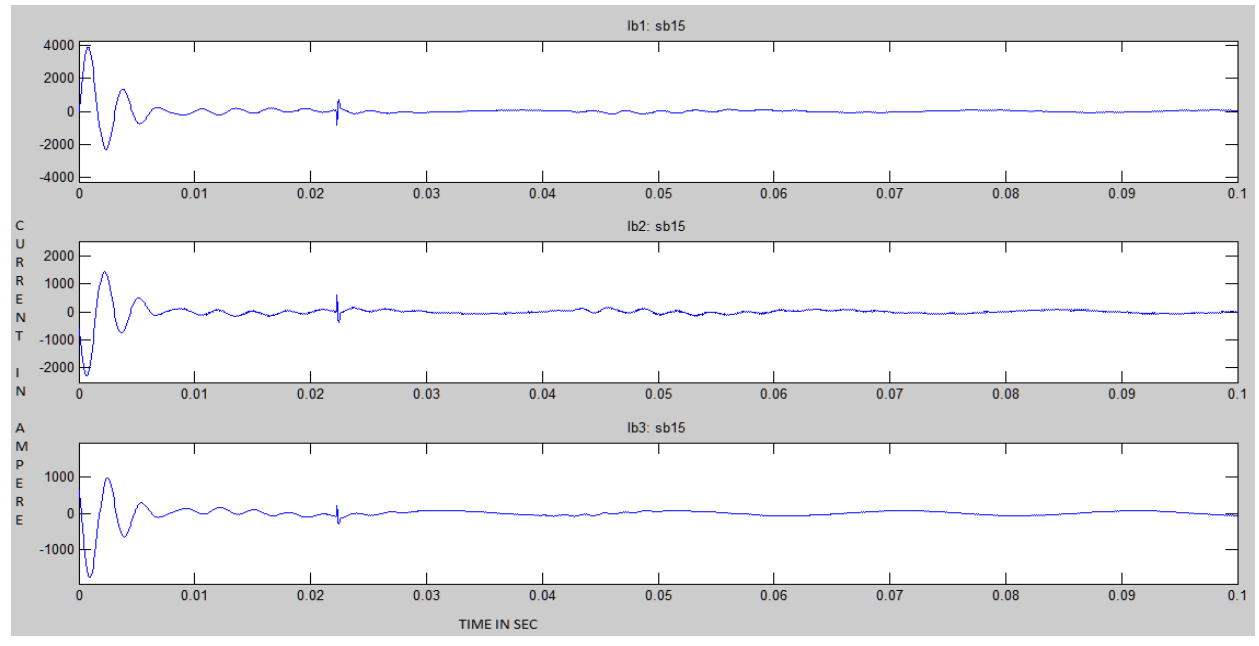

Figure 11. Current Waveform of Bus 10 without SVC

\subsection{Current Waveform of Bus 10 with SVC}

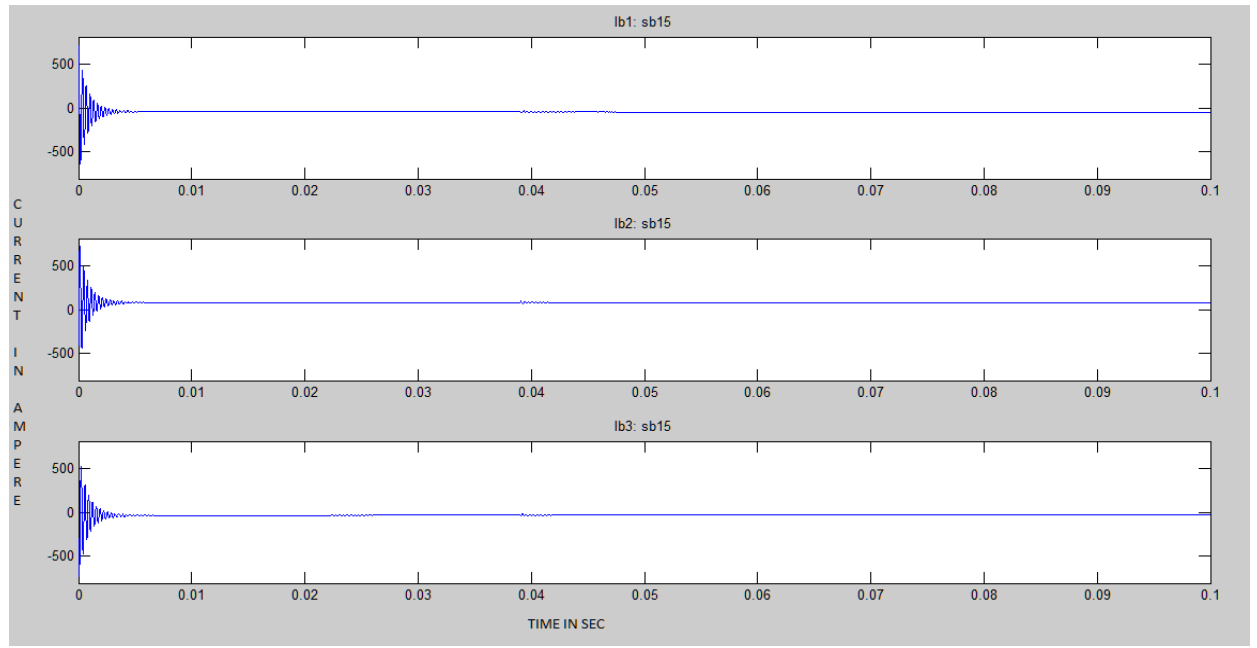

Figure 12. Current Waveform of Bus 10 with SVC 


\subsection{Voltage Waveform of Bus 1 without Compensator}

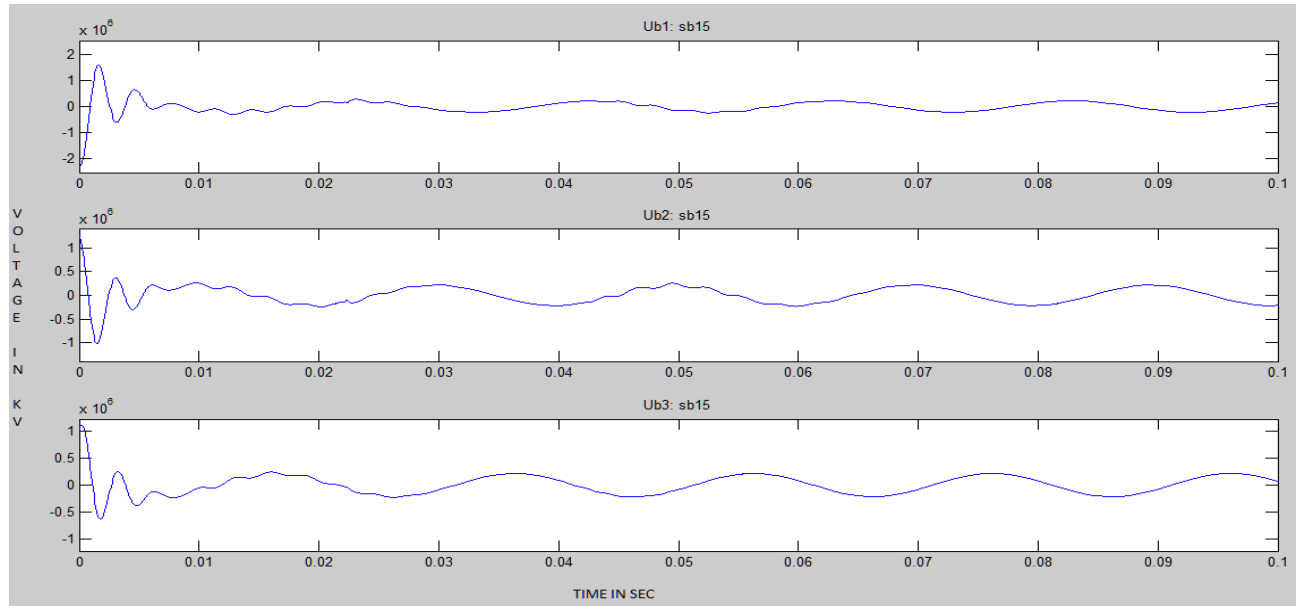

Figure 13. Voltage Waveform of Bus 1 without Compensator

\subsection{Voltage Waveform of Bus 1 with Compensator}

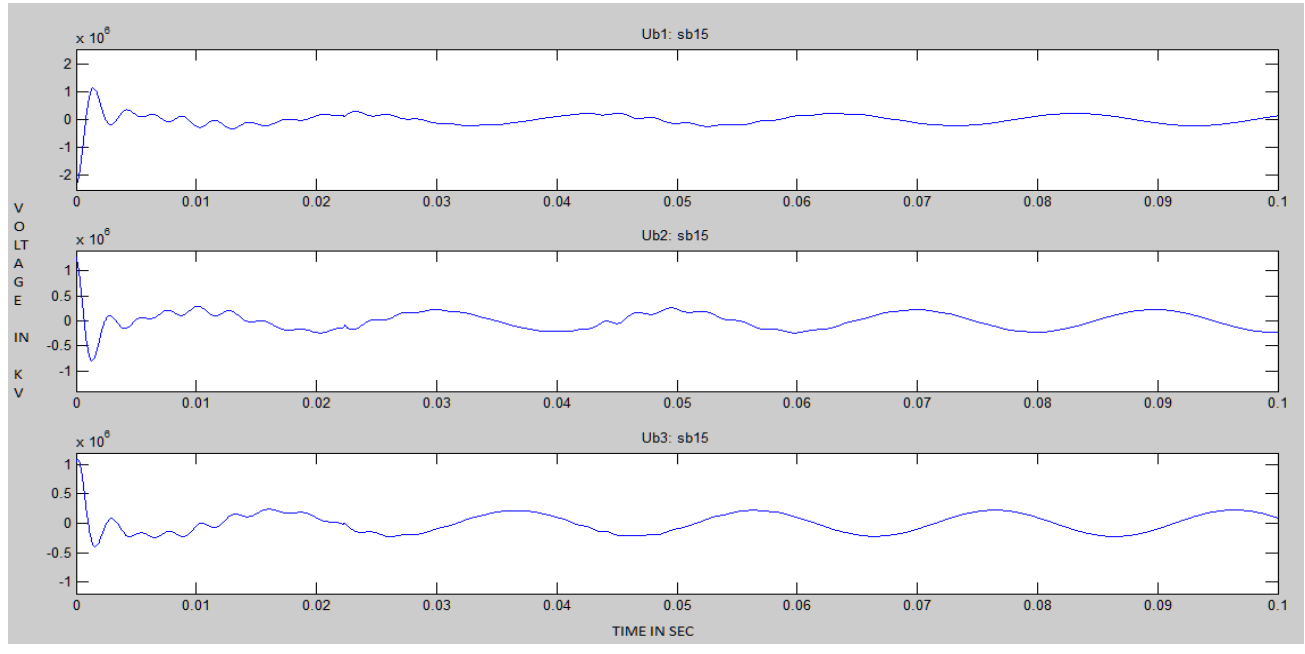

Figure 14. Voltage Waveform of Bus 1 with Compensator

\subsection{Current Waveform of Bus 1 without Series Compensator}

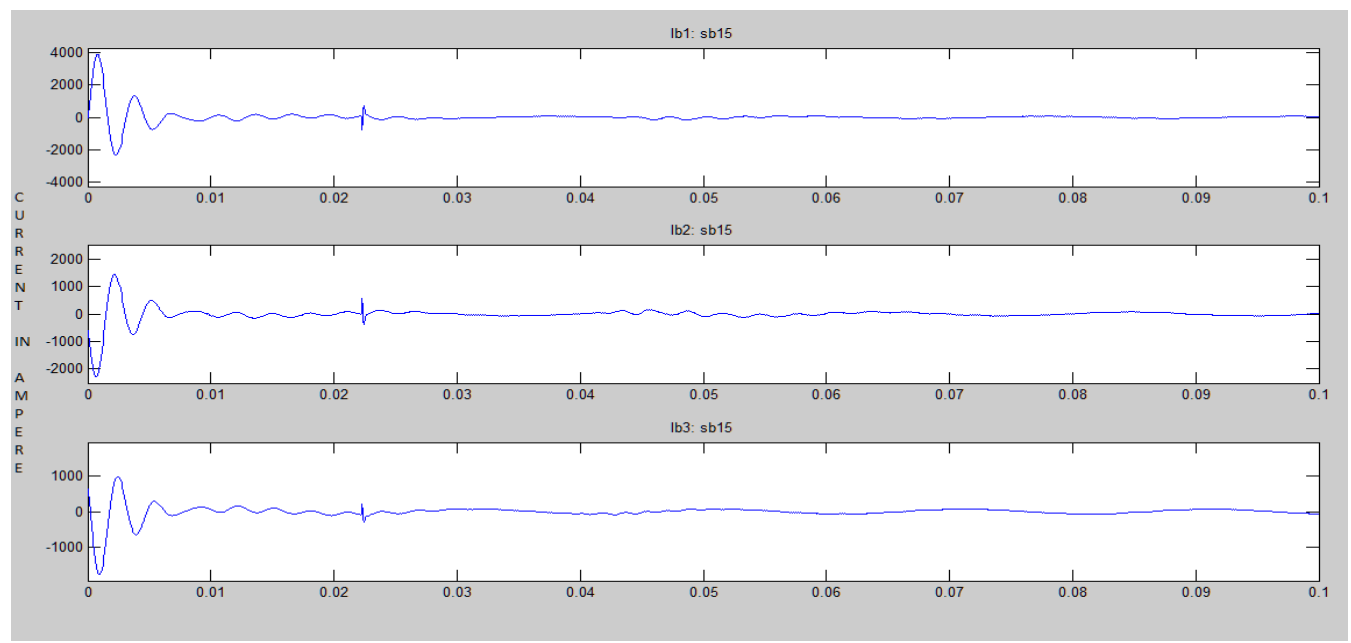

Figure 15. Current Waveform of Bus 1 without Series Compensator 


\subsection{Current Waveform of Bus 1 with Series Compensator}

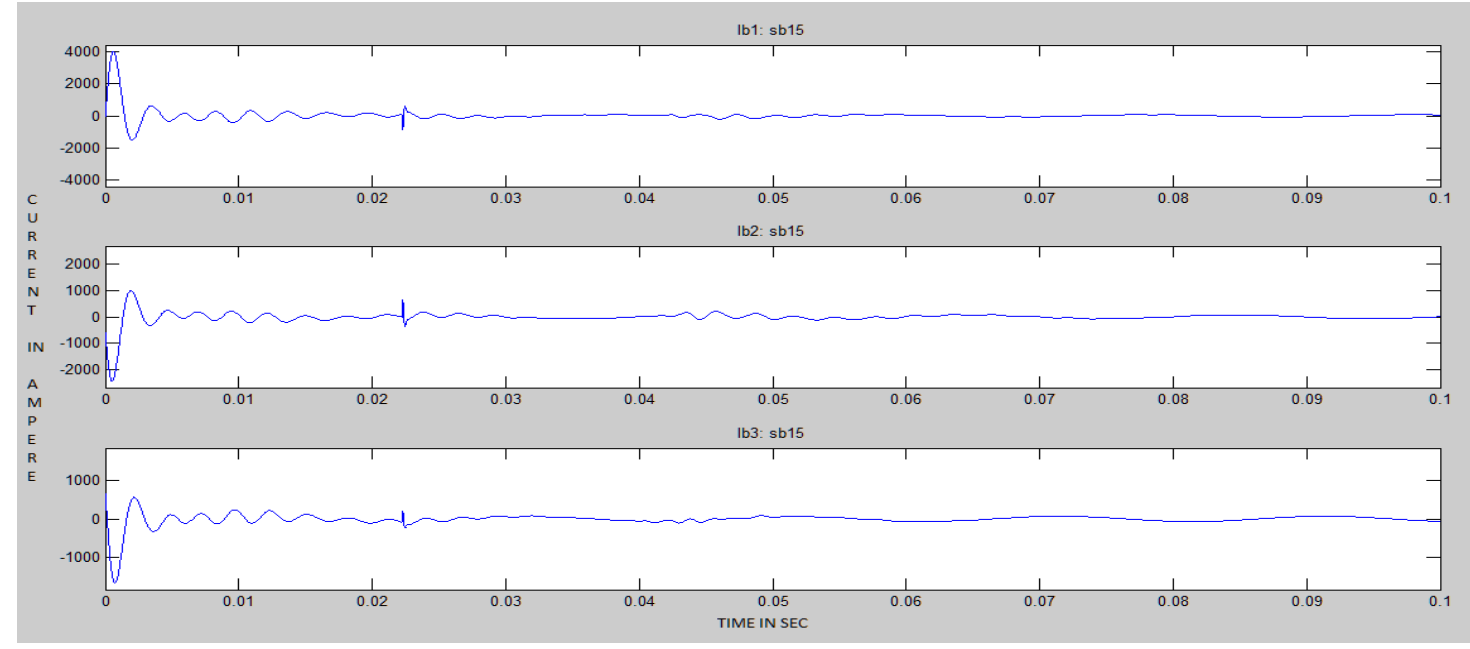

Figure 16. Current Waveform of Bus 1 with Series Compensator

Table 1. Line and transformer data for 11-bus system

\begin{tabular}{lllll}
\hline From bus & To bus & R pu & X pu & $1 / 2$ B pu \\
\hline 1 & 2 & 0.00 & 0.06 & 0.0000 \\
2 & 3 & 0.08 & 0.30 & 0.0004 \\
2 & 5 & 0.04 & 0.15 & 0.0002 \\
2 & 6 & 0.12 & 0.45 & 0.0005 \\
3 & 4 & 0.10 & 0.40 & 0.0005 \\
3 & 6 & 0.04 & 0.40 & 0.0005 \\
4 & 6 & 0.15 & 0.60 & 0.0008 \\
4 & 9 & 0.18 & 0.70 & 0.0009 \\
4 & 10 & 0.00 & 0.08 & 0.0000 \\
5 & 7 & 0.05 & 0.43 & 0.0003 \\
6 & 8 & 0.06 & 0.48 & 0.0000 \\
7 & 8 & 0.06 & 0.35 & 0.0004 \\
7 & 11 & 0.00 & 0.10 & 0.0000 \\
8 & 9 & 0.052 & 0.48 & 0.0000 \\
\hline
\end{tabular}

\section{Conclusion}

The system is modeled without and with SVC to observe the phenomena of transient oscillation and subsequently how it is damped out by the SVC. It is found that the SVC can effectively damp out the resulting oscillating. In the result part we have compared the outputs of two models with and without SVC. Thus it has been clearly observed that the transient oscillations sustain up to $0.03 \mathrm{sec}$ without SVC and with the use of SVC the transient oscillation vanishes before $0.01 \mathrm{sec}$. Further it has been observed that with use of series compensator the fault amplitude for current and voltages at different buses reduces and transmission capacity increases thus improving the power transfer capability.

\section{References}

[1] L. Gyugyi, \ Reactive Power Generation and Control by Thyristor Circuits" IEEE Trans., v. IA-15, n.5, 1979, pp.521531

[2] A.Olwegard et al, Improvement of Transmission Capacity by Thyristor Controlled Reactive Power", IEEE Trans .v. PAS100, 1981, pp. .3930-3939.

[3] R.M. Mathur, Editor, Static Compensators for Reactive Power Control, Canadian Electrical Association, Cantext Publications, Winnipeg, 1984

[4] A. E. Hammad, "Analysis of power system stability enhancement by static var compensators", IEEE Trans. On Power Systems, vol. 1, No. 4, pp. 222-227, 1986.

[5] M. O'Brien and G.Ledwich, I Static Reactive Power Compensator Controls for Improved System Stability", IEEE Proc., v.134, Pt.c, n.1, 1987, pp.38-42

[6] L.Gyugyi, \Power Electronics in Electric Utilities: Static Var Compensators", Proc. IEEE, v. 76, n.4, 1988, pp.483-494

[7] L. Gyugyi, "Power Electronics in Electric Utilities : Static Var Compensators" in Proc. IEEE' 76, paper 4, p. 483-494, 1988.

[8] K. R. Padiyar and R.K.Varma, IConcepts of Static Var System Control for Enhancing Power Transfer in Long Transmission Lines", Electric machines and Power Systems, v.18, 1990, pp.337-358

[9] K. R. Padiyar, and R. K. Verma, "Concepts Of Static VAR System Control For Enhancing Power Transfer In Long Transmission Lines", Electric Machines and Power Systems, vol. 18, p. 337-358, 1990.

[10] K. R. Padiyar and R.K. Varma, \Damping Torque Analysis of Static Var System controller ", IEEE Trans., Power Systems, v.6, n.2, 1991, pp.458-465

[11] P. Kundur, Power System Stability and Control, EPRI Power System Engineering Series, New York, McGraw-Hill Inc, 1994. 
[12] V. Rajkumar and R. R. Mohler, \Nonlinear control methods for power systems : A comparison", IEEE Trans. on Control Systems Technology, v. 3, n. 2, 1995, pp. 231-237.

[13] V. Venkatasubramanian, K.W. Schneider and C.W. Taylor, Improving Pacific intertie stability using existing static VAR compensators and Thyristor Controlled Series Compensation", Bulk Power System Dynamics and Control IV \{ Restructuring, Santorini, Greece, August

[14] N. G. Hingorani, and L. Gyugyi, Understanding FACTS, Concept and Technology of Flexible AC Transmission Systems, New York, Wiley Publishers, 2000.

[15] H. Saadat, Power System Analysis, Tata McGraw-Hill, 2002.

[16] G. Sybille and P. Giroux, " Simulation of FACTS Controllers using the MATLAB Power System Blockset and Hypersim Real-Time Simulation", IEEE PES, Panel Session Digital Simulation of FACTS and Custom-Power Controllers Winter Meeting, New York, p. 488-49, 2002.

[17] M. H. Hague, "Improvement of first stability limit by utilizing full benefit of shunt FACTS devices", IEEE Transactions On Power Systems, vol. 19, no.4, pp. 1894 1902,2004
[18] IEEE TASK FORCE: "Proposed Terms and Definitions for Flexible AC Transmission, vol.12, No.4, Systems (FACTS)", IEEE Trans. On Power Delivery 2005.

[19] S. Panda, and Ramnarayan M. Patel, "Improving Power System Transient Stability with an. Off-Centre Location of Shunt Facts Devices ", Journal of Electrical Engineering, vol. 57, No. 6, 2006

[20] K. R. Padiyar, FACTS Controllers in Power Transmission and Distribution, New Age International Publishers, 2007.

[21] A. Ghosh, D. Chatterjee, "Transient Stability Assessment of Power Systems Containing and Shunt Compensators", Power Systems, IEEE Transactions on Power Delivery, vol. 22, no.3, p. Series 1210-1220, Aug. 2007.

[22] A. A. Edris, R. Aapa, M. H. Baker, L. Bohman and K. Clark, "Proposed Terms and Definitions for Flexible Ac Transmission Systems (FACTS)", IEEE Trans. On Power

[23] V. Mahajan, "Power System Stability Improvement with Flexible A .C. Transmission System (FACTs) Controller," Power System Technology an IEEE Power India Conference, POWERCON 2008. 